\title{
Mitigation of Amphotericin B Nephrotoxicity by Mannitol
}

\author{
JUAN J. OLIVERO, JOSE LOZANO-MENDEZ， ELIAS M. GHAFARY， GARABED EKNOYAN, \\ WADI N. SUKI
}

British Medical fournal, 1975, 1, 550-551

\section{Summary}

Renal transplant recipients are susceptible to a number of fungal infections amenable to therapy with amphotericin $B$, but azotaemia is an almost invariable sequel to the use of this agent. As intravenous mannitol has been shown to minimize nephrotoxicity induced by amphotericin $B$ in dogs we treated four kidney transplant recipients who had systemic fungal infections with mannitol and amphotericin B. None showed significant reduction in renal function though a mild metabolic acidosis did develop.

\section{Introduction}

Since its introduction in 1956 amphotericin B has become the drug of choice for treating systemic mycoses. This drug belongs to the polyene antibiotic group and is available as a microcrystalline suspension in water or as a colloidal suspension. The latter is the only useful form for treating systemic mycoses in man, the route of administration varying according to the severity, extent, and site of infection. It has been administered directly into the subarachnoid space (including basal cistern, lateral ventricles, and lumbar subarachnoid space); subcutaneously; into various cavities, especially the intrathoracic, intraarticular, and intraocular cavities; and into the lungs either by aerosol or through a semipermanent endobronchial catheter (Butler, 1966). In general, systemic disease calls for intravenous therapy, and 2-4 $\mathrm{g}$ is usually sufficient for most mycotic infections (Miller and Bates, 1969).

Because of its nephrotoxic effects the dose given is to some extent governed by its toxic rather than its therapeutic effects. This becomes particularly problematic in patients with chronic debilitating and terminal diseases or end-stage renal disease or in transplanted patients on immunosuppressive drugs, who are particularly susceptible to systemic fungal infections. The use of potentially nephrotoxic agents in these patients must be considered in the light of their life-saving effect. Additionally, in the patient with a transplant, immunosuppression may have to be discontinued and an otherwise adequately functioning allograft may need to be sacrificed to combat the infection. Any way of minimizing nephrotoxicity would therefore be a major therapeutic advance.

Mannitol diuresis to reduce the nephrotoxicity of amphotericin B has a beneficial effect in dogs (Hellebusch et al., 1972). So far as we know our report on the use of mannitol in four renal transplant recipients who needed amphotericin B therapy (see table) is the first account of the successful use of this combination therapy.

Renal Section, Baylor College of Medicine and Methodist and Veterans Administration Hospitals, Houston, Texas JUAN J. OLIVERO, M.D., Research Fellow in Nephrology ELIAS M. GHAFARY, M.D., Research Fellow in Nephrology

Department of Medicine, Baylor College of Medicine and Methodist and Veterans Administration Hospitals, Houston, Texas JOSE LOZANO-MENDEZ, M.D., Instructor

GARABED EKNOYAN, M.D., F.A.C.P., Professor of Medicine WADI N. SUKI, M.D., P.A.C.P., Professor of Medicine

\section{Case Reports}

Case 1.-A 32-year-old man with end-stage renal failure secondary to chronic glomerulonephritis was started on chronic haemodialysis early in 1968. Three months later he received a renal allograft from his mother. Maintenance immunosuppression consisted of azathioprine $50 \mathrm{~m}$ and prednisone $25 \mathrm{mg}$ daily. In August 1971 he developed cellulitis in the right thigh and left arm associated with ulceration in the posterior right arm and fever $\left(38.9^{\circ} \mathrm{C}\right.$.) Chest $x$-ray pictures showed a miliary infiltrate not present on a film obtained a few weeks earlier. Histoplasma was recovered from the skin ulcers and the lungs, and the patient was begun on a regimen of amphotericin $B$ intravenously twice a week in progressive doses up to $50 \mathrm{mg}$, preceded and followed by $12.5 \mathrm{~g}$ of mannitol to a total dose of $2.0 \mathrm{~g}$. The endogenous creatinine clearance, which was $33 \mathrm{ml} / \mathrm{min}$ on addmission, remained unaltered and was $37 \mathrm{ml} / \mathrm{min}$ at the end of therapy. Ammonium chloride, $0 \cdot 1 \mathrm{~g} / \mathrm{kg}$, however, failed to cause a lowering of urine $\mathrm{pH}$ below $5 \cdot 9$.

Case 2.-A 49-year-old man was admitted to hospital for evaluation of headache and fever after a 'flu-like syndrome for about three weeks. Five years previously he had received a cadaveric kidney transplant and was on long-term immunosuppression (azathioprine $200 \mathrm{mg}$ daily and methylprednisolone $24 \mathrm{mg}$ on alternating days) as well as isoniazide $300 \mathrm{mg}$ daily. Spinal fluid culture grew cryptococcus and he was begun on amphotericin B intravenously in progressive doses up to $50 \mathrm{mg}$ daily. He received mannitol $12.5 \mathrm{~g}$ intravenously immediately before and after each dose and completed his total therapy of $3 \mathrm{~g}$ of amphotericin B as an outpatient. The serum urea nitrogen and the serum creatinine, which on admission were $26.4 \mathrm{mmol} / 1(37 \mathrm{mg} / 100 \mathrm{ml})$ and $195 \mu \mathrm{mol} / 1(2.2 \mathrm{mg} / 100 \mathrm{ml})$ respectively, were $19.3 \mathrm{mmol} / 1(27 \mathrm{mg} / 100 \mathrm{ml})$ and $122 \mu \mathrm{mol} / 1(2.4 \mathrm{mg} / 100$ $\mathrm{ml})$ when therapy was completed.

Case 3.-A 42-year-old man was admitted to hospital for evaluation and treatment of epigastric pain and vomiting of about two weeks duration. Six months previously he had received a cadaveric kidney transplant and was maintained on azathioprine $50 \mathrm{mg}$ daily and prednisone $15 \mathrm{mg}$ every other day. He admitted to frequent beer drinking, a diagnosis of pancreatitis was established, and he was begun on intravenous fluids and nasogastric suction. On discontinuance of the suction pain and raised amylse levels recurred. Three days later while in hospital an abdominal mass developed which was subsequently shown to be a pancreatic pseudocyst. Because of the need for long-term nasogastric suction feeding was begun via a subclavian line, and he was given broad-spectrum antibiotics for recurring fever without obvious site of origin. About five days after intravenous feeding was begun the urine sediment was noted to contain candida. Candida septicaemia seeding the kidney was suspected. The tip of the subclavian catheter grew candida though the blood cultures were negative. Amphotericin B was started in progressive daily doses in association with mannitol $12.5 \mathrm{~g}$ intravenously before and after the infusion of the drug. The patient received a total of $775 \mathrm{mg}$ of amphotericin $\mathrm{B}$. His blood urea nitrogen on discharge from the hospital was 7.9 $\mathrm{mmol} / 1(11 \mathrm{mg} / 100 \mathrm{ml})$ and the serum creatinine $80 \mu \mathrm{mol} / 1(0.9 \mathrm{mg} /$ $100 \mathrm{ml})$.

Case 4.-A 49-year-old man with renal failure secondary to nephrosclerosis was started on dialysis in February 1973 and received a kidney transplant from his brother in March 1974. On azathioprine $250 \mathrm{mg}$ and prednisone $50 \mathrm{mg}$ daily his serum creatinine had been stable at below $177 \mu \mathrm{mol} / 1(2 \mathrm{mg} / 100 \mathrm{ml})$. An oropharyngeal infection with multiple white spots on the tongue, gums, and pharynx failed to respond to nystatin and led to his readmission in June 1974 because of fever, sore throat, and pain in the sinuses. X-ray examination showed congestion of the right maxillary sinus, which was drained and cultured. Cultures grew Staphylocuccus aureus, but pathological examination revealed mucormycosis. In addition to methicillin for the staphylococcus, he was treated with progressively increasing doses of amphotericin B reaching $50 \mathrm{mg} /$ day in six days. Doses of amphoteri- 
Clinical and Laboratory Data on Four Kidney Transplant Recipients treated with Amphotericin B and Mannitol

\begin{tabular}{|c|c|c|c|c|c|c|c|c|c|c|c|c|c|}
\hline \multirow{2}{*}{$\begin{array}{l}\text { Case } \\
\text { No. }\end{array}$} & \multirow{2}{*}{$\underset{\text { (Years) }}{\text { Age }}$} & \multirow{2}{*}{$\begin{array}{l}\text { Fungal } \\
\text { Infection }\end{array}$} & \multirow{2}{*}{$\begin{array}{l}\text { Total Dose of } \\
\text { Amphotericin B } \\
\text { (mg) }\end{array}$} & \multicolumn{3}{|c|}{$\begin{array}{c}\text { Blood Urea Nitrogen } \\
(\mathrm{mmol} / \mathrm{l})^{*}\end{array}$} & \multicolumn{3}{|c|}{$\begin{array}{l}\text { Serum Creatinine } \\
(\mu \mathrm{mol} / 1)^{*}\end{array}$} & \multicolumn{3}{|c|}{$\underset{(\mathrm{mmol} / \mathrm{l})^{*}}{\operatorname{Serum}}$} & \multirow{2}{*}{$\begin{array}{l}\text { Renal } \\
\text { Disease }\end{array}$} \\
\hline & & & & 1 & 2 & 3 & 1 & 2 & 3 & 1 & 2 & 3 & \\
\hline 1 & 32 & Histoplasmosis & 1885 & $17 \cdot 9$ & $29 \cdot 3$ & $22 \cdot 1$ & 195 & 265 & 212 & 24 & 19 & 22 & Chronic \\
\hline 2 & 49 & Cryptococcosis & 3000 & $26 \cdot 4$ & $32 \cdot 1$ & $27 \cdot 1$ & 195 & 237 & 221 & 27 & 23 & 23 & $\begin{array}{l}\text { Chronic } \\
\text { glomerulonephritis }\end{array}$ \\
\hline 3 & 42 & Candidiasis & 775 & $10 \cdot 7$ & $13 \cdot 6$ & $5 \cdot 7$ & 106 & 133 & 80 & 25 & 18 & 21 & $\begin{array}{l}\text { Chronic } \\
\text { glomerulonephritis }\end{array}$ \\
\hline 4 & 49 & Mucormycosis & 1685 & $10 \cdot 7$ & $15 \cdot 7$ & $13 \cdot 6$ & 106 & 150 & 115 & 25 & 22 & 20 & Nephrosclerosis \\
\hline
\end{tabular}

*Value 1 is that obtained on admission; 2 the most abnormal value during therapy; 3 value obtained at end of treatment.
Conversion: SI to Traditional Units-Creatinine: $1 \mu \mathrm{mol} / 1 \approx 0.0113 \mathrm{mg} / 100 \mathrm{ml}$. Blood urea nitrogen: $1 \mathrm{mmol} / 1 \approx 1.4 \mathrm{mg} / 100 \mathrm{ml}$.

cin B were preceded and followed by $12.5 \mathrm{~g}$ of mannitol. After a total dose of amphotericin B of $1685 \mathrm{mg}$ the renal function remained stable with a serum urea nitrogen of $13.6 \mathrm{mmol} / 1(19 \mathrm{mg} / 100 \mathrm{ml})$ and creatinine of $115 \mu \mathrm{mol} / 1(1.3 \mathrm{mg} / \mathrm{ml} \mathrm{100})$. A short ammonium chloride loading test showed failure to lower urine $\mathrm{pH}$ to below $5 \cdot 75$.

\section{Discussion}

The pharmacokinetics of amphotericin B in regard to tissue distribution and metabolism are poorly understood. It has been suggested that renal damage is dose-related and that the likelihood of nephrotoxicity rises greatly when the total dose exceeds $5 \mathrm{~g}$ (Butler et al., 1964 a). Possibly the response to the drug is unpredictable and individual (Miller and Bates, 1969). In patients with normal renal function $2 \cdot 5-13 \%$ of the administered dose will appear in the urine in its active form during the 24 hours after a single infusion (Feldman et al., 1973). With repeated infusions of the same dose the range is $2-5 \%$. Plasma half life is about 24 hours, but after an initial rapid fall the decline is gradual. Only $40 \%$ of a single dose is excreted in the urine after seven days. The fate of the unexcreted portion is unknown. Evidence that it may be stored in the reticuloendothelial system has been advanced, and the drug can be detected in blood and urine for up to four weeks later. The role of the kidney in eliminating amphotericin $\mathrm{B}$ does not seem to be important as shown in studies of the pharmacokinetics of this drug in an anephric patient (Feldman et al., 1973).

The following nephrotoxic effects of amphotericin B have been reported: decreased glomerular filtration rate (Bell et al., 1962), renal arteriolar vasoconstriction (Butler et al., 1964 b), tubular degeneration and nephrocalcinosis (Wertlake et al., 1963), decreased concentrating ability (Holeman and Einstein, 1963), hypokalaemia and renal potassium wasting (Eknoyan and Roberts, 1962), and renal tubular acidosis (Patterson and Ackerman, 1971). Most of these abnormalities are reversible if detected early and the drug stopped or its rate of administration reduced, but this often leads to inadequate therapy and progression of the infectious process. To circumvent this process efforts to reduce the toxicity of this agent have included using alternate-day therapy, hydrocortisone, heparin, and antihistamines. Perhaps more important has been the demonstration in rats of the partially protective effect of simultaneously administered bicarbonate (Gouge and Andriole, 1971). Rats receiving bicarbonate had only partial impairment of creatinine clearance and of the maximum concentrating and acidifying capacities when compared to rats given amphotericin B alone. Since in-vitro studies have shown enhancement by amphotericin $\mathrm{B}$ of the passive permeability of cells to hydrogen ion (Lampen, 1969) the beneficial effect of bicarbonate has been attributed to alkalinization of the urine and protection of the distal tubular cells from injury due to intracellular acidification. A beneficial effect of bicarbonate administration has also been suggested in some human studies (McCurdy et al., 1968).
Hellebusch et al. (1972) observed no significant deterioration of renal function in dogs treated simultaneously with amphotericin B and mannitol. Though no direct measurements of renal blood flow were made they presumed that mannitol prevented the reduction of renal blood flow secondary to the renal vasoconstriction which occurs with amphotericin B (Butler et al., $1964 \mathrm{~b})$. Mannitol protects against the development of acute renal failure (Teschan et al., 1966), and the demonstration of the prevention of mannitol of endothelial cell swelling that follows renal arterial pedicle clamping in the dog (Flores et al., 1972) lends further support to this concept.

Our report shows the application of this form of therapy to man. In our four cases no significant change in serum urea nitrogen or creatinine was noted after successful treatment of the underlying infection with amphotericin B. Systemic acidosis was not prevented, however, and all four patients had some degree. In two patients who were tested with the short oral ammonium chloride loading test inability to maximally acidify the urine was found. This suggests that the azotaemia may be a vasomotor phenomenon while the renal acidosis is possibly the consequence of a specific tubular toxicity of the drug. Since bicarbonate protects against the tubular defect and the development of metabolic acidosis (Gouge and Andriole, 1971) it seems reasonable to assume that its effect is exerted at a site different from that of mannitol. On the basis of our experience with mannitol and the experimental data on bicarbonate we suggest that patients receiving amphotericin $\mathrm{B}$ should receive bicarbonate in addition to mannitol to circumvent more fully both postulated mechanisms of renal injury - the vascular effect and the cellular injury.

This work was supported by training grants from the National Kidney Foundation (Dr. Olivero) and the National Heart and Lung Institute (HL 05963, Dr. Ghafary).

\section{References}

Bell, N. H., et al. (1962). American fournal of Medicine, 33, 64.

Butler, W. T., et al. $(1964$ b). Fournal of Pharmacology and Experimenta Therapeutics, 143, 47

Butler, W. T. (1966). Fournal of the American Medical Association, 195, 371 Eknoyan, G., and Roberts, A. D. (1962). Antimicrobial Agents and Chemotherapy, 2, 497.

Feldman, H. A., Hamilton, J. D., and Gutman, R. A. (1973). Antimicrobia Agents and Chemotherapy, 4, 302.

Flores, J., et al. (1972). Fournal of Clinical Investigation, 51, 118.

Gouge, T. H., and Andriole, V. T. (1971). Fournal of Laboratory and Clinical Medicine, 78, 713 .

Hellebusch, A. A., Salama, F., and Eadie, E. (1972). Surgery, Gynecology and Obstetrics, 134, 241.

Holeman, C. W., jun., and Einstein, H. (1963). California Medicine, 99, 90. Lampen, J. O. (1969). American fournal of Clinical Pathology, 52, 138. McCurdy, D. K., Frederic, M., and Elkinton, J. R. (1968). New England fournal of Medicine, 278, 124 .

Miller, R. P., and Bates, J. H. (1969). Annals of Internal Medicine, 71, 1089. Patterson, R. M., and Ackerman, G. L. (1971). Archives of Internal Medicine, 127, 241 .

Teschan, P. E., and Dawson, N. L. (1966). Nephron, 3, 1.

Wertlake, P. T., et al. (1963). American fournal of Pathology, 43, 449. 